\title{
Study of primary caesarean section in multigravida patients
}

\author{
Neelam Rajput ${ }^{1}$, Priyanka Singh ${ }^{1 *}$, Yogendra Singh Verma ${ }^{2}$
}

\begin{abstract}
${ }^{1}$ Department of Obstetrics and Gynecology, ${ }^{2}$ Department of Pediatrics, Kamla Raja Hospital, G R Medical College Gwalior, Madhya Pradesh, India
\end{abstract}

Received: 22 October 2017

Accepted: 17 November 2017

\author{
*Correspondence: \\ Dr. Priyanka Singh, \\ E-mail: neelamkrhgwl@rediffmail.com
}

Copyright: (c) the author(s), publisher and licensee Medip Academy. This is an open-access article distributed under the terms of the Creative Commons Attribution Non-Commercial License, which permits unrestricted non-commercial use, distribution, and reproduction in any medium, provided the original work is properly cited.

\begin{abstract}
Background: Caesarean section is the most commonly performed major surgery among women. The aims and objective of this study was to know the incidence of primary Caesarean section in multigravidas, its indications and to know the maternal and foetal outcome among these patients.

Methods: It was a prospective study of primary caesarean section in multigravida admitted at Kamla Raja Hospital, G.R. Medical College and J. A. Group of Hospitals, Gwalior (Madhya Pradesh, India) during the period of 1 year from September 2014 to August 2015. Multigravida with pregnancy of $>28$ weeks gestation (gravida 2 and above), each of whom has had a previous vaginal delivery of $>20$ weeks gestation were included. Women with previous abortions and previous section and Pregnancy with medical disorders were excluded.

Results: During the study period of one year, total 8185 deliveries occurred, out of which $3061(37.39 \%)$ underwent caesarean section and $386(12.61 \%)$ were primary caesarean section in multigravida. Out of these multigravida patients who underwent primary caesarean section- most of the patients were unbooked (77.72\%). Majority of the cases were direct admission in the hospital (61.13\%). Maximum number of the patients were in the age group of 2530 years $(55.95 \%)$. Two third of the patients were literate $(69.44 \%)$ Maximum number of patients were Gravida 2 $(49.72 \%)$. Almost all of them $(95.85 \%)$ underwent emergency caesarean section. The most common indication for primary LSCS in multigravida patients was Malpresentation 115 (29.79\%) followed by Fetal distress in 71 (18.39\%) patients, APH in 71 (18.39\%), Obstructed labour in 33 (8.55\%), Severe preeclampsia and Antepartum eclampsia in 39 (10.1\%), Twin pregnancy in $21(5.44 \%)$. Most common maternal complication was pyrexia 40 (10.36\%). Postoperative morbidity was $21.24 \%$ among unbooked, $14.25 \%$ in Referred, $23.58 \%$ in those operated as an emergency, $12.43 \%$ in patients belonging to of low socioeconomic status and $3.88 \%$, in patients with moderate to severe anemia. Birth asphyxia was found in $6.21 \%$ of neonates. Neonatal mortality was $2.33 \%$. Neonatal mortality is more in Unbooked cases $(90.47 \%)$.

Conclusions: Many unforeseen complications occur in women who previously had a normal vaginal delivery. It is recommended that all antenatal patients must be booked and receive proper and regular antenatal care. Also $100 \%$ deliveries in multigravida should be institutional deliveries in order to reduce maternal and perinatal morbidity and mortality.
\end{abstract}

Keywords: Multigravida, Maternal outcome, Neonatal outcome, Primary caesarean section

\section{INTRODUCTION}

Caesarean section is the most commonly performed major surgery in women in current years and can be life saving for the child, the mother, or both in certain cases. Caesarean births have become safer due to improved anaesthetic and surgical techniques, availability of broad spectrum antibiotics, blood and blood products and better 
understanding for timely decision for caesarean section. This is not to imply that they have become safer than normal uncomplicated vaginal deliveries but have become safer than they used to be. ${ }^{1}$

Different study related the rise in caesarean section to a change in medical practice and concluded that although indications did not change much over the time, there has been lowering in the overall threshold concerning the decision to carry out a caesarean section. ${ }^{1-4}$

There are many factors that contribute to the variations in caesarean section rates, such as practice culture, practice style, hospital environment, and source of payment, patient's preference, and socioeconomic status. A clinical practice guideline can reduce the caesarean section rates without increasing adverse outcomes (SuwanrathKengpol C 2004). ${ }^{5}$ High or rising rates of caesarean delivery do not necessarily reflect demand for surgical delivery. ${ }^{6}$

Multipara means those who had delivered once or more after the age of viability. It includes primi-para (uniparapara 1) multipara (para 2, 3, 4) and grand multipara (para more than 4$){ }^{7}$ Primary caesarean section in the multipara means first caesarean section done in the patients who had delivered vaginally once or more. Mainly the baby and the placenta are responsible for caesarean section in multipara.

Multipara may still have cephalopelvic disproportion even having previously delivered a full term child vaginally. Since the foetus increases in size with multiparity, the size of foetus and foetal head should be carefully estimated. In multiparous patients, malpresentations are favored by a pendulous abdomen and lordosis of the lumbar spine and in any case, that is usual for the head not to engage in the pelvis until the onset of labour. $^{8}$

Multiparity is a problem associated with poverty, illiteracy, ignorance and lack of knowledge of the available antenatal care and family planning methods. A multipara who has earlier delivered vaginally may still require a caesarean section for safe delivery. ${ }^{1}$

It is a common belief amongst public that once a mother delivers her child or children normally, all her subsequent deliveries will be normal. As a result, such multiparous mothers often neglect routine antenatal checkup. ${ }^{8}$ It is for these reasons that attention has been directed to the indication for caesarean section in women who have previously delivered vaginally. ${ }^{9}$

There are several indications of caesarean sections, chiefly severe contraction of the pelvis, other forms of dystocia, major degree of placenta previa and severe preeclampsia and eclampsia. ${ }^{11}$ The other indications include fetal distress, bad obstetric history $(\mathrm{BOH})$ and difficult vaginal operative delivery. However the indications of caesarean section are not limited to the obstetrics and medical factors, but also extend to various socioeconomic, ethical, and medicolegal factors resulting in an alarming increase in caesarean section rate all over the world. ${ }^{12}$

Defensive obstetrics is another common cause for high rate of caesarean section. It has been observed that $82 \%$ of physicians performed caesarean to avoid negligence claims. Vaginal delivery takes around 12 hours against 30 minutes to perform caesarean section thus heavily taxing upon obstetrician time and patience. ${ }^{13}$

Present study has been done to study the indications and outcome of caesarean section being done in multigravida who had earlier delivered successfully by vaginal route.

\section{METHODS}

It was a prospective study of all the cases of primary caesarean section in multigravida admitted at Kamla Raja Hospital, G.R. Medical College and J.A. Group of Hospitals, Gwalior (M.P.) during a period of 1 year from September 2014 to August 2015.

Permission from ethical committee of the institution was obtained. Study was done in parous women who had previous vaginal deliveries

Inclusion Criteria was all Multigravida with pregnancy of $>28$ weeks gestation (gravida 2 and above), each of whom has had a previous vaginal delivery of $>20$ weeks gestation.

Women with previous abortions and previous section and Pregnancy with medical disorders were excluded from the study.

Information was collected in a predesigned proforma about demographic profile, obstetric history, physical examination, indication of cesarean section, maternal and perinatal outcome.

\section{Statistical analysis}

The chi-squared test was used for comparative analysis of categorical variables in order to determine independent risk factors Statistical significance was defined as $\mathrm{P}$ $<0.05$. SPSS 17.0 software (SPSS, Chicago, IL, USA) was used.

\section{RESULTS}

A prospective study of primary caesarean section in multigravida admitted at Kamla Raja Hospital, G.R. Medical College and J.A. Group of Hospitals, Gwalior (M.P.) during a period of 1 year from September 2014 to August 2015 and a total of $386(12.61 \%)$ patients were 
selected for study and following observations were made. Total number of deliveries during the study period of 1 year was 8185. Caesarean section was done in 3061 $(37.39 \%)$ patients.

Table 1: Nutritional status of study subjects.

\begin{tabular}{|lll|}
\hline $\begin{array}{l}\text { Parameters } \\
\text { Anemia }\end{array}$ & No. of patients & Percentage \\
\hline Normal Hb & 130 & 33.68 \\
\hline Mild & 215 & 55.70 \\
\hline Moderate & 31 & 8.03 \\
\hline Severe & 8 & 2.07 \\
\hline Very severe & 2 & 0.52 \\
\hline BMI & & \\
\hline Underweight & 74 & 19.17 \\
\hline Normal & 284 & 73.57 \\
\hline Overweight & 26 & 6.74 \\
\hline Obesity & 2 & 0.52 \\
\hline
\end{tabular}

Out of 386 patients, most of them were unbooked $(77.72 \%)$ and direct admission $(61.13 \%)$, only 150 $(38.86 \%)$ patients were referred from different places.

Most of the patients $216(55.95 \%)$ belong to the age group of 26-30 years followed by 123 (31.86\%) in age $21-25$ years, $41(10.62 \%)$ patients in age group of $31-35$ years. Only 5 patients $(1.29 \%)$ were above 35 years of age.

Period of gestation in 229 of the patients $(59.33 \%)$ was $37-40$ weeks followed by 111 patients $(28.76 \%)$ in $32-36$ weeks, 12 patients $(3.10 \%)$ in $28-31$ weeks of gestational age and 8 patients $(2.07 \%)$ were in gestational period of $>40$ weeks.

Distribution of patients according to education showed that most of them were having primary education 179 (46.37\%). About $118(30.56 \%)$ patients were illiterate followed by $84(21.76 \%)$ patients who had secondary education and only $5(1.29 \%)$ patients were graduates. This also reflects the improved literacy rates in last few years.

Distribution of socioeconomic class on the basis of modified Kuppuswamy Scaler most of the patients shows majority $(54.1 \%)$ were from upper lower class followed by $139(36 \%)$ patients in lower class, 37 (9.6\%) patients from lower middle class and only one $(0.30 \%)$ patient was found to be from upper middle class.

Type of work distribution reveals that Most of the patients were Moderate worker 298 (77.20\%), followed by heavy worker $80(20.72 \%)$ and only $8(2.07 \%)$ were sedentary workers. Nutritional status of the patients (Table 1) shows that only $34 \%$ of woman had normal Hemoglobin level but majority $(73.5 \%)$ had normal BMI. Out of 386 cases $370(95.85 \%)$ of patients underwent
Emergency caesarean section whereas only 16 (4.15\%) patients were operated Electively.

Table 2: Indications of primary caesarean section in multigravida.

\begin{tabular}{|lll|}
\hline Indication & $\begin{array}{l}\text { No. of } \\
\text { patients }\end{array}$ & Percentage \\
\hline Malpresentations & 115 & 29.79 \\
\hline Breech & 63 & 16.32 \\
\hline Face & 4 & 1.03 \\
\hline Brow & 3 & 0.78 \\
\hline Compound presentation & 3 & 0.78 \\
\hline Cord presentation & 1 & 0.26 \\
\hline Cord prolapsed & 4 & 1.03 \\
\hline Transverse lie & 36 & 9.32 \\
\hline Oblique lie & 1 & 0.26 \\
\hline Cephalopelvic disproportion & 36 & 9.32 \\
\hline Antepartum hemorrhage & 71 & 18.39 \\
\hline Placenta previa & 65 & 16.84 \\
\hline Abruptio placentae & 6 & 1.55 \\
\hline Fetal distress & 71 & 18.39 \\
\hline Obstructed labour & 33 & 8.55 \\
\hline Severe preeclampsia and & 39 & 10.1 \\
\hline anterartum eclampsia & 21 & 5.44 \\
\hline Twin pregnancy & 386 & 100.0 \\
\hline Total & & \\
\hline
\end{tabular}

Most common indication for caesarean section (Table 2) in present study was Malpresentation 115 (29.79\%), followed by Fetal distress in $71(18.39 \%)$ patients, APH in $71(18.39 \%)$, Preeclampsia and Eclampsia in 39 $(10.1 \%)$, Obstructed labour in $33(8.55 \%)$ patients and Cephalopelvic disproportion each and Twin pregnancy in $21(5.44 \%)$.

Table 3: Maternal outcome.

\begin{tabular}{|lll|}
\hline Maternal outcome & No. of patients & Percentage \\
\hline Healthy & 295 & 76.42 \\
\hline Postoperative morbidity & 91 & 23.57 \\
\hline Abdominal distention & 6 & 1.55 \\
\hline Pyrexia & 40 & 10.36 \\
\hline URTI & 32 & 8.29 \\
\hline Wound infection & 11 & 2.85 \\
\hline PPH & 2 & 0.52 \\
\hline Total & 386 & 100 \\
\hline
\end{tabular}

Most of patients $300(77.72 \%)$ did not require blood transfusion and only $86(22.28 \%)$ patients received blood transfusion. Analysis of maternal outcome (Table 3) shows that out of 386 patients, $91(23.57 \%)$ patients had different complications. Most common maternal complication was pyrexia in $40(10.36 \%)$ patients, followed by Upper respiratory tract infection in 32 $(8.29 \%)$ patients, wound infection in $11(2.85 \%)$ patients and abdominal distention in $6(1.55 \%)$ patients. Correlation of post operative maternal morbidity with various risk factors (Table 4) reveals that most of the 
patients having postop morbidity were Unbooked (21.24\%), Referred (14.25\%), operated in emergency $(23.58 \%)$, of low socioeconomic status $(12.43 \%)$, with moderate to severe anemia (3.88\%), who are underweight $(9.58 \%)$, or overweight $(2.59 \%)$, having low level of education $(11.13 \%)$ and moderate to heavy worker.

Table 4: Correlation of post operative maternal morbidity with various risk factors.

\begin{tabular}{|c|c|c|c|c|c|}
\hline Parameters & Healthy & $\%$ & Post-op morbidity & $\%$ & $P$ value \\
\hline \multicolumn{6}{|c|}{ Booking status } \\
\hline Unbooked & 218 & 56.47 & 82 & 21.24 & \multirow{2}{*}{0.001} \\
\hline Booked & 77 & 19.95 & 9 & 2.33 & \\
\hline \multicolumn{6}{|c|}{ Direct/Referred } \\
\hline Direct & 200 & 51.81 & 36 & 9.33 & \multirow{2}{*}{$<0.001$} \\
\hline Referred & 95 & 24.61 & 55 & 14.25 & \\
\hline \multicolumn{6}{|c|}{ Emergency/Elective } \\
\hline Emergency & 279 & 72.28 & 91 & 23.58 & \multirow{2}{*}{0.023} \\
\hline Elective & 16 & 4.15 & 0 & 0 & \\
\hline \multicolumn{6}{|c|}{ Socioeconomic status } \\
\hline Lower & 91 & 23.57 & 48 & 12.43 & \multirow{4}{*}{0.0001} \\
\hline Upper lower & 171 & 44.04 & 38 & 9.84 & \\
\hline Lower middle & 32 & 8.29 & 5 & 1.29 & \\
\hline Upper middle & 1 & 0.26 & 0 & 0 & \\
\hline \multicolumn{6}{|c|}{ Nutritional status } \\
\hline \multicolumn{6}{|l|}{ Anemia } \\
\hline Normal $\mathrm{Hb}$ & 106 & 27.46 & 21 & 5.44 & \multirow{4}{*}{$<0.024$} \\
\hline Mild & 160 & 41.45 & 55 & 14.25 & \\
\hline Moderate & 18 & 4.66 & 11 & 2.85 & \\
\hline Severe & 6 & 1.55 & 4 & 1.03 & \\
\hline \multicolumn{6}{|l|}{ BMI } \\
\hline Underweight & 37 & 9.58 & 37 & 9.58 & \multirow{4}{*}{$<0.001$} \\
\hline Normal & 242 & 62.69 & 42 & 10.88 & \\
\hline Overweight & 16 & 4.15 & 10 & 2.59 & \\
\hline Obese & 0 & 0 & 2 & 0.52 & \\
\hline \multicolumn{6}{|c|}{ Educational status } \\
\hline Uneducated & 75 & 19.43 & 43 & 11.13 & \multirow{4}{*}{$<0.001$} \\
\hline Primary & 139 & 36.01 & 40 & 10.36 & \\
\hline Secondary & 76 & 19.68 & 8 & 2.07 & \\
\hline Graduate & 5 & 1.29 & 0 & 0 & \\
\hline \multicolumn{6}{|l|}{ Type of work } \\
\hline Sedentary & 7 & 1.81 & 1 & 0.25 & \multirow{3}{*}{0.45} \\
\hline Moderate & 228 & 59.06 & 70 & 18.13 & \\
\hline Heavy & 60 & 15.54 & 20 & 5.18 & \\
\hline
\end{tabular}

Table 5: Neonatal morbidity.

\begin{tabular}{|lll|}
\hline Morbidity & No. of neonates & Percentage \\
\hline Healthy Neonates & 295 & 76.42 \\
\hline $\begin{array}{l}\text { Neonates with } \\
\text { some morbidity }\end{array}$ & 72 & 18.65 \\
\hline Birth Asphyxia & 24 & 6.21 \\
\hline Sepsis and Pyrexia & 13 & 3.36 \\
\hline MAS & 11 & 2.84 \\
\hline RDS & 22 & 5.69 \\
\hline CHD & 1 & 0.26 \\
\hline Conjoint twin & 1 & 0.26 \\
\hline $\begin{array}{l}\text { RDS; Respiratory distress } \\
\text { aspiration syndrome, CHD; Congenital Heart Disease }\end{array}$ \\
\hline
\end{tabular}

On Analysis of baby weight, we find that half of the babies were in the weight range of $2.5-3.0 \mathrm{Kg}$ whereas $32.5 \%$ were in the range of $2.5-1.5 \mathrm{~kg}$. Only 9 babies $(2.33 \%)$ were below $1.5 \mathrm{~kg}$ and 40 babies were above $3 \mathrm{~kg}$. There were 19 IUD.

The most common morbidity present in neonates (Table 5) was birth asphyxia in $4(6.21 \%)$ neonates followed by RDS in $22(5.69 \%)$ neonates, sepsis and pyrexia in 13 $(3.36 \%)$ and MAS in $11(2.84 \%)$ of neonates.

The most common reason for mortality was Birth Asphyxia $9(42.85 \%)$ followed by RDS in $6(28.57 \%)$ 
patients and sepsis and pyrexia in $2(9.52 \%)$ patients and MAS in $2(9.52 \%)$, CHD in 1(4.76\%) (Figure 1).

Common indication of caesarean section which led to neonatal mortality were placenta previa (most of the neonates were premature), Obstructed labour, Transverse lie with cord prolapse.

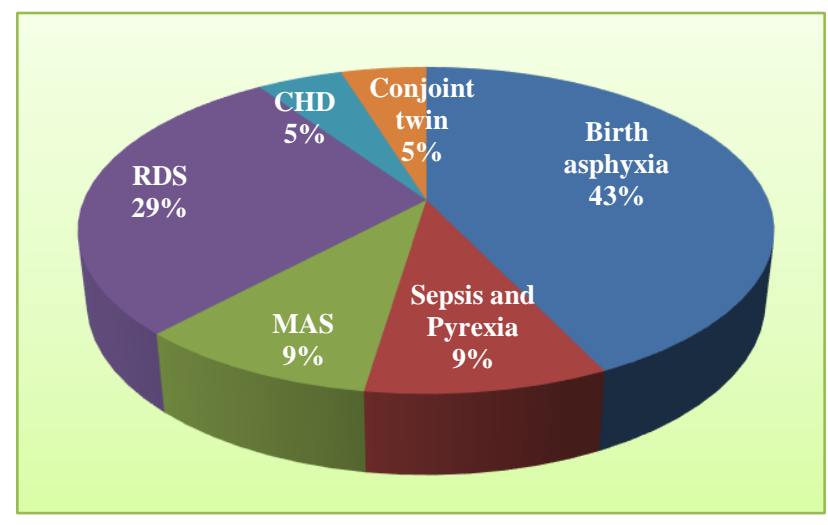

Figure 1: Causes of perinatal mortality.

\section{DISCUSSION}

A prospective study was done in Department of Obstetrics and Gynecology at Kamla Raja Hospital, G.R. Medical College, Gwalior (M.P.) during the period of 1 year from September 2014 to August 2015. A total of 386 subjects of Primary Caesarean section on multigravida were selected for the study with inclusion and exclusion criterias.

A multipara who has earlier delivered vaginally may still require a caesarean section for safe delivery. ${ }^{1}$

Total number of deliveries during the study period of 1 year was 8185 and the total number of caesarean section was 3061 with a caesarean section rate of $37.39 \%$ (table 1). Himabindu $P$ et al found a comparable caesarean section rate of $40 \%$ in her study. ${ }^{14}$ The high caesarian section rate in our institution was because Kamla Raja hospital is a tertiary referral center having a wide catchment area. Out of 3061 caesarean section 1077 $(35.18 \%)$ were done in primigravida and $386(12.61 \%)$ in multigravida. Repeat caesarean section was done in 1598 $(52.20 \%)$ patients (Table 2).

Among 386 study subjects 300 patients (77.72\%) were unbooked. This fact reveals poor level of antenatal booking of the patients in India particularly in M.P. This may be because of low level of female literacy and lack of public awareness regarding the need for antenatal checkup. Our results are comparable with the study done by Desai E et al (72.09\%) and Himabindu $\mathrm{P}$ et al $(71 \%) .{ }^{1,14}$

A total of 236 patients $(61.13 \%)$ were direct admission in the hospital and only $150(38.86 \%)$ patients were referred from different places (Table 4). The finding reflects lower number of institutional deliveries in M.P. Most of the cases were direct admission and came to hospital only when some complications occurred. Almost similar results were reported by Desai E et al, who found that the cases which were received directly rather than referred were more in numbers $(48.84 \%){ }^{1}$

Out of 386 patients, most of the patients $(55.95 \%)$ belong to age group of $26-30$ years followed by $31.86 \%$ to the age group 21-25 years (Table 5). This is because in India legal age of marriage for the girls is 18 years. Sethi $\mathrm{P}$ et al also reported in his study that maximum number of women undergoing primary caesarean section were from the age group of 25-29 years $(41 \%){ }^{2}$ Unnikrishnan B et al also reported the similar results. ${ }^{15}$

Distribution of patients according to parity shows that most of the patients $(49.73 \%)$ were Gravida-2 followed by Gravida-3 $(32.12 \%)$. It reflects that in the last few years' family size has been shifted from 5-6 children per couple to 2-3 children per couple. Grand multiparity has been significantly reduced in the past few years. Sethi $\mathrm{P}$ et al also reported the similar results $35 \%$ Gravida-2, 30\% of Gravida-3 parity status. ${ }^{2}$

Most of the patients (59.33\%) belong to gestational period of $37-40$ weeks followed by $(28.76 \%)$ period of 32-36 weeks. Rowaily MA et al reported in his study on primary cesarean section in multigravida found that most the patients $(78.8 \%$ )belong to gestational age of $37-42$ weeks followed by $18.2 \%$ patients in gestational age of $<37$ weeks, the results are comparable to present study. ${ }^{16}$

Distribution of patients according to education status showed that most of them were having primary education $(46.37 \%)$ and $30.56 \%$ patients were illiterate. Study done by Ajeet $\mathrm{S}$ et al shows better education status in his study. ${ }^{17}$

Most of the patients $(54.1 \%)$ belong to upper lower class followed by $36 \%$ patients in lower class. This is because of the fact that in Madhya Pradesh $31.65 \%$ population is still living below poverty line. Ajeet $\mathrm{S}$ et al also reported that in his study done on 247 patients, maximum patients $(41.3 \%)$ were from class III socioeconomic class. ${ }^{17}$

Out of total 386 patients, $215(55.70 \%)$ of patients had mild anemia, $31(8.03 \%)$ of patients had moderate anemia and $8(2.07 \%)$ and $2(0.52 \%)$ of patients had severe and very severe. The incidence of Anemia in antenatal patients in India is reported in $>80 \%$ patients.

Most of the patients (95.85\%) underwent Emergency caesarean section and only $16(4.15 \%)$ had elective caesarean section. Study done by Sethi $\mathrm{P}$ et al in 100 patients showed almost similar results showing $91 \%$ emergency operative and only $9 \%$ were electively operated. $^{2}$ 
In present study most, common indication for caesarean section was Malpresentations 115 (29.79\%) followed by Fetal distress in $71(18.39 \%)$, APH in $71(18.39 \%)$, Severe Preeclampsia and Eclampsia in $39(10.1 \%)$, Obstructed labour and Cepahalopelvic disproportion in $33(8.55 \%)$ each, Twin pregnancy in $21(5.44 \%)$. Rao JH et al also reported Abnormal presentations (32.5\%), APH (19.5\%), Fetal distress (17\%), obstructed labour (18.5\%) in her study ${ }^{3}$. Desai $\mathrm{E}$ et al also reported fetal distress (25.58\%), APH (22.09\%), CPD (19.77\%) and abnormal presentations $(17.44 \%)$ as the most common indications for caesarean sections in his study. ${ }^{1}$ Himabindu $\mathrm{P}$ et al also reported fetal distress $(24.7 \%)$ as the most common indication for Caesarean section in his study he also showed that most common abnormal presentation was breech for which caesarian section was done. ${ }^{14}$

Out of 386 patients $87(22.54 \%)$ received blood transfusion. Study done by Rouse DJ et al reported that those women who undergo primary caesarean, only $3.2 \%$ required blood transfusion. ${ }^{18}$ Higher number of requirement for transfusion could be because of the fact that incidence of anaemia among pregnant women is very high in India (>80\%).

Out of 386 patients, 91 (23.57\%) patients had different complications. Most common maternal complication was pyrexia in $40(10.36 \%)$ patients followed by URTI in 32 $(8.29 \%)$ patients, wound infection in $11(2.85 \%)$ patients and abdominal distention in $6(1.55 \%)$ patients. Rao $\mathrm{JH}$ has shown almost similar results in his study. ${ }^{3}$ In the present study, there was no maternal mortality observed. This may be because of availability of better antibiotics, blood and blood product transfusion facilities, safe methods of anesthesia, timely intervention, better surgical techniques and operative skill of obstetrician. ${ }^{2}$

Postoperative morbidity was statistically significantly higher in unbooked patients, referred patients, Emergency LSCS, low socioeconomic status, anemia, Obesity, lower level of education. There was no statistically significant difference among the various groups according to level of activity.

Baby weight was $2.5-3.5 \mathrm{~kg}$ in $58.29 \%$ of cases and $34.97 \%$ baby were below $2.5 \mathrm{~kg}$, only 7 babies $(181 \%)$ were above $3,5 \mathrm{Kg}$. Rowaily MA et al in his study done on 4307 patients reported that most of the babies $(61.7 \%)$ born were having weight of 2500-3500 grams which is considered to be a normal body weight followed by $21.6 \%$ babies who had body weight of $>3500$ grams. Lower baby weight in our study could be a reflection of poor maternal nutrition and antenatal care. ${ }^{16}$

The most common morbidity present in neonates was Birth asphyxia in $24(6.21 \%)$ neonates followed by RDS in $22(5.69 \%)$ neonates, sepsis and pyrexia in $13(3.36 \%)$ patients and MAS in $11(2.84 \%)$ patients. Sethi $P$ analysed perinatal morbidity and reported birth asphyxia in $4 \%$, sepsis and pyrexia in $4 \%$, meconium aspiration syndrome (MAS) in 3\%, convulsions in 3\% and respiratory distress syndrome (RDS) in 3\% patients. Results are comparable in both study. ${ }^{2}$

The most common reason for mortality was Birth asphyxia $9(42.85 \%)$ followed by RDS in $6(28.57 \%)$ patients and sepsis and pyrexia in $2(9.52 \%)$ patients. The incidence of perinatal mortality in present study was $5.44 \%$. Omar AA et al also reported high perinatal mortality among the caesarean delivery $(11.1 \%)$ and the main cause of death was severe birth asphyxia. ${ }^{6}$

Neonatal mortality is more in case of Unbooked cases $(90.47 \%)$ it is because of lack of antenatal care, poor maternal nutrition, unattended medical complications and maternal morbidities and prolonged trial at home. All of them unbooked cases underwent Emergency Caesarean section. Out of all neonatal deaths $57.14 \%$ were referred cases, most of neonates $13(61.90 \%$ ) were of $<1.5 \mathrm{Kg}$ birth weight and no neonatal mortality occurred in neonate of $>2.5 \mathrm{~kg}$ birth weight. Common indication of caesarean section which led to neonatal mortality were placenta previa (most of the neoantes were premature), Obstructed labour, Transverse lie with cord prolapse.

From the above discussion it is reemphasized that Multigravida is more often neglected women having low attention of family. The fact that once a woman delivers vaginally during her first or second pregnancy the family as well as the patient herself are reluctant and less attentive to regular antenatal checkup which leads to increased incidence of anemia, poor nutrition, lack of early diagnosis of malpresentation, placenta previa. And the fact that she has delivered normally family is reluctant also for institutional delivery and most of the patients delivered by untrained person at home and they seek medical care only when multiple complication become obvious, and this is the matter of worry. From the above discussion it is reemphasized that the women in India need to be empowered by better education so that she herself and the family are aware of the possible complications during pregnancy and delivery, and to avoid them regular antenatal checkups, early diagnosis of pregnancy and its high risk factors, and their management is possible. Our National targets are to reduce Maternal mortality rate below 100/lacs live births and Neonatal mortality rate below 29/1000 live births. This can be achieved by female literacy rate by $>80 \%$ and $100 \%$ good quality antenatal care and $100 \%$ institutional deliveries.

\section{Funding: No funding sources \\ Conflict of interest: None declared \\ Ethical approval: The study was approved by the Institutional Ethics Committee}

\section{REFERENCES}

1. Desai E, Leuva H, Leuva B, Kanani M. A study of primary caesarean section in multipara. Int $\mathrm{J}$ Reprod Contracept Obstet Gynecol. 2013;2(3):320-4. 
2. Sethi P, Vijaylaxmi S, Shailaja G, Bodhare T, Devi S. A study of primary caesarean section in multigravidae. Perspect Med Res. 2014;2:3-7.

3. Rao JH, Rampure N. Study of primary caesarean section in multiparous women. J Evol Med Dental Sci. 2013;2(24):4-7.

4. Registrar General, India, 2009 and Office of Registrar General, India, 2011.

5. Suwanrath-Kengpol C, Pinjaroen S, Krisanapan O, Petmanee P. Effect of a clinical practice guideline on physician compliance. Int J Quality Health. 2004; 16:327-332.

6. Omar AAA, Anza SA. Frequency Rate and Indications of Caesarean Sections at Prince Zaid Bin Al Hussein Hospital-Jordan. JRMS. 2012;19(1):82-6.

7. Solomon B. The dangerous multipara. Lancet 1932;2:8-11.

8. Basak S, Lahri D. Dystocia in eutocic multigravida. J Obstet Gynecol India. 1975;25:502-7.

9. Jacob S, Bhargava H. Primary caesarean section in multipara. J Obstet Gynaecol India. 1972;22(6):64250 .

10. Marfatlal SJ, Narendrabhi MM. Analysis of mode of delivery in women with previous one caesarean section, J Obstet Gynecol India. 2009;59(2):136-9.

11. Hickl EJ. The safety of caesarean section. In: Popkin DR and Peddle LJ, Eds. Women's Health Today. London: Parthenon Publishers. 1994:65-70.

12. Vijaykrishnan M, Bhaskar Rao K. Caesarean deliveries - Changing Trends. In: Arulkumaran S, Ratnam SS, Bhasker Rao K (Editors). The
Management of Labour, $2^{\text {nd }} \mathrm{Ed}$, Hyderabad, Orient Longman;2005:351-63.

13. WHO: Monitoring Emergency Obstetric Care: A Handbook. Geneva, Switzerland: World Health Organization 2009.

14. Himabindu P, Sundari MT, Sireesha KV, Sairam MV. Primary caesarian section in multipara. IOSRJDMS. 2015;14(5):22-5.

15. Unnikrishnan B, Rakshith P, Aishwarya A, Nithin K, Rekha T, Prasanna $\mathrm{P}$ et al. Trends and Indications for Caesarean Section in a tertiary care Obstetric Hospital in Coastal South India. AMJ. 2010;3(12):821-5.

16. Rowaily MA, Fahad A, Alsalem, Mostafa A Abolfotouh. Caesarean section in a high-parity community in Saudi Arabia: clinical indications and obstetric outcomes. BMC Pregnancy Childbirth. 2014;14(92):1-10.

17. Ajeet S, Jaydeep N, Nandkishore K, Nisha R. Women's knowledge, perceptions, and potential demand towards caesarean section. Natl $\mathbf{J}$ Community Med. 2011;2(2):244-8.

18. Rouse DJ, MacPherson C, Landon M, Varner MW, Leveno KJ, Moawad AH et al. Blood transfusion and caesarean delivery. Obstet Gynecol. 2006 Oct;108(4):891-7.

Cite this article as: Rajput N, Singh P, Verma YS. Study of primary caesarean section in multigravida patients. Int J Reprod Contracept Obstet Gynecol 2018;7:185-91. 